\title{
Inter-study reproducibility of circumferential strain and strain rates at 1.5T and 3T: a comparison of tagging and feature tracking
}

\author{
Anvesha Singh ${ }^{1,2^{*}}$, Christopher D Steadman ${ }^{3}$, Jamal N Khan ${ }^{1,2}$, Sheraz A Nazir ${ }^{1,2}$, Prathap Kanagala ${ }^{1,2}$, \\ Gerry P McCann ${ }^{1,2}$
}

From 17th Annual SCMR Scientific Sessions

New Orleans, LA, USA. 16-19 January 2014

\section{Background}

Feature Tracking (FT) is a relatively new technique for measuring strain on cardiac magnetic resonance imaging (CMR), that has been shown to have reasonable interstudy reproducibility (Coefficient of variation $(\mathrm{CoV})$ $\sim 20 \%$ ) in healthy volunteers. The inter-study reproducibility of FT has not yet been reported in any patient groups, nor compared to that of MRI tagging. We sought to determine the inter-study reproducibility of circumferential strain and strain rates using FT and tagging at $1.5 \mathrm{~T}$ and $3 \mathrm{~T}$ scanners, in patients with moderate-severe Aortic Stenosis (AS).

\section{Methods}

CMR was performed twice in 8 patients with severe AS on a $1.5 \mathrm{~T}$ scanner and 10 patients with moderate-severe AS at 3T. Three short-axis tagged images were acquired, in addition to the standard SSFP short-axis cine stack. InTag (Creatis, Lyon, France) in OsiriX (Geneva, Switzerland) was used to calculate the Circumferential Peak Systolic Strain (PSS), Peak Systolic Strain Rate (PSSR) and Peak Early Diastolic Strain Rate (PEDSR). Diogenes CMR FT (TomTec Imaging Systems, Munich, Germany) was used to calculate the same parameters on nearest SSFP cine images.

\section{Results}

Overall, FT gave higher strain and strain rate values when compared to tagging. On paired sample t-tests, there was no significant difference in the strain and strain rate values between scan one and scan two, using both tagging and FT, at both $1.5 \mathrm{~T}$ and 3T. The inter-study reproducibility of both techniques was higher at $1.5 \mathrm{~T}$ compared to 3T. (Table 1, Figure 1) Comparing tagging vs FT, PSS was more reproducible with FT at both $1.5 \mathrm{~T}$ and 3T, while PSSR was more reproducible with tagging. PEDSR demonstrated similar inter-study reproducibility using both techniques, but was much more reproducible at 1.5T than 3T. (CoV's for circumferential PSS, PSSR and PEDSR at 1.5T- FT: 8.6, 11.8 and 13.1\%, tagging: 12.2, 9.4 and 17.5\%; CoV's at 3T-FT: 9.4, 23 and $25.6 \%$, tagging: $17.9,19.3$ and $32.5 \%)$.

\section{Conclusions}

Both tagging and FT have good reproducibility at $1.5 \mathrm{~T}$ and modest reproducibility at 3T scanners. This may partly be due to greater artefacts at $3 \mathrm{~T}$. Overall, FT appears to have higher reproducibility than tagging for circumferential PSS, while PSSR is more reproducible with tagging. If the main parameter of interest is PEDSR, scanning at $1.5 \mathrm{~T}$ and using FT is more preferable. Given that FT does not require additional image acquisitions and involves shorter post-processing time, this technique is likely to become the preferred method for strain and strain rate quantification with CMR.

\section{Funding}

This work is part of a Project Grant funded by the British Heart Foundation (PG/07/068/2334). Support also received from the NIHR Leicester Cardiovascular Biomedical Research Unit. 
Table 1 Inter-study reproducibility of global Circumferential strain and strain rates using Tagging and FT on 1.5T and 3T scanners.

\begin{tabular}{|c|c|c|c|c|c|c|c|}
\hline Scanner & Technique & Parameter & Average Value+ & Paired Mean Difference (SD) & Limits of agreement & R (Pearson's Correlation) & CoV \\
\hline \multirow[t]{6}{*}{$1.5 \mathrm{~T}$} & Tagging & PSS & $-16.86 \pm 2.78$ & $-0.33(2.06)$ & -4.36 to 3.70 & $0.78^{*}$ & 12.2 \\
\hline & & PSSR & $-0.80 \pm 0.08$ & $-0.01(0.07)$ & -0.16 to 0.14 & 0.60 & 9.4 \\
\hline & & PEDSR & $1.00 \pm 0.31$ & $0.02(0.18)$ & -0.33 to 0.36 & $0.82^{*}$ & 17.5 \\
\hline & FT & PSS & $-20.88 \pm 2.26$ & $-0.14(1.81)$ & -3.68 to 3.39 & 0.70 & 8.6 \\
\hline & & PSSR & $-1.34 \pm 0.27$ & $0.00(0.16)$ & -0.31 to 0.31 & $0.81^{*}$ & 11.8 \\
\hline & & PEDSR & $1.24 \pm 0.31$ & $0.11(0.16)$ & -0.21 to 0.43 & $0.86^{*}$ & 13.1 \\
\hline \multirow[t]{6}{*}{$3 T$} & Tagging & PSS & $-17.59 \pm 2.86$ & $-0.30(3.14)$ & -6.46 to 5.86 & 0.36 & 17.9 \\
\hline & & PSSR & $-0.99 \pm 0.25$ & $-0.13(0.19)$ & -0.50 to 0.25 & $0.67^{*}$ & 19.3 \\
\hline & & PEDSR & $0.82 \pm 0.26$ & $0.05(0.27)$ & -0.47 to 0.57 & 0.46 & 32.5 \\
\hline & FT & PSS & $-20.94 \pm 3.43$ & $-0.82(1.97)$ & -4.67 to 3.04 & $0.86^{*}$ & 9.4 \\
\hline & & PSSR & $-1.21 \pm 0.31$ & $-0.19(0.28)$ & -0.74 to 0.35 & 0.59 & 23.0 \\
\hline & & PEDSR & $1.23 \pm 0.37$ & $0.20(0.30)$ & -0.40 to 0.79 & 0.61 & 25.6 \\
\hline
\end{tabular}

Abbreviations: PSS: peak systolic strain, PSSR: peak systolic strain rate, PEDSR: peak early diastolic strain rate, CoV: Coefficient of variation. Average of epicardial and endocardial contours used for FT. No significant difference between scan-1 and scan-2 values on paired sample $t$-test; *Statistically significant correlation ( $p$ $<0.05),+$ Average of all values from scan 1 and 2.

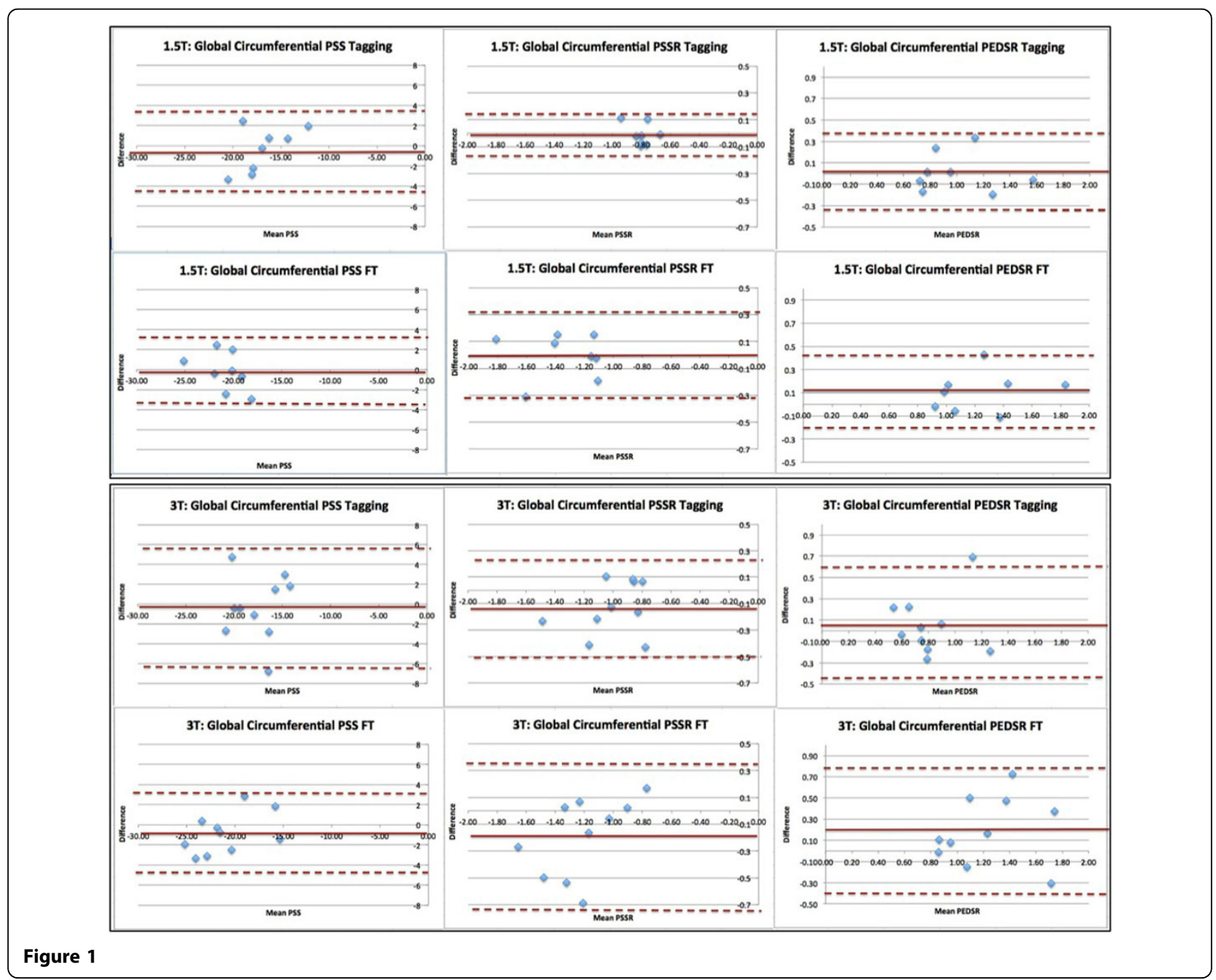




\section{Authors' details}

${ }^{1}$ Cardiovascular Sciences, University of Leicester, Leicester, Leicestershire, UK.

${ }^{2}$ Cardiology, Glenfield Hospital, Leicester, Leicestershire, UK. ${ }^{3}$ Cardiology,

Poole Hospital NHS Foundation Trust, Poole, UK.

Published: 16 January 2014

doi:10.1186/1532-429X-16-S1-P354

Cite this article as: Singh et al: Inter-study reproducibility of

circumferential strain and strain rates at 1.5T and $3 \mathrm{~T}$ : a comparison of tagging and feature tracking. Journal of Cardiovascular Magnetic

Resonance 2014 16(Suppl 1):P354.

Submit your next manuscript to BioMed Central and take full advantage of:

- Convenient online submission

- Thorough peer review

- No space constraints or color figure charges

- Immediate publication on acceptance

- Inclusion in PubMed, CAS, Scopus and Google Scholar

- Research which is freely available for redistribution

Submit your manuscript at www.biomedcentral.com/submit

() BioMed Central 